\title{
Pesticide use linked to Parkinson's disease
}

David Adam

Long-term low-level exposure to a pesticide widely used in horticulture and water management could be a cause of Parkinson's disease in humans, researchers at Emory University in Georgia warned this week.

They found that rats given repeated doses of the insecticide rotenone, which is derived from plant extracts, have difficulty walking, shaky paws, and protein deposits in their brains - all tell-tale symptoms of Parkinson's disease.

The results, which appear to strengthen existing epidemiological evidence of a link between pesticide exposure and Parkinson's, were announced at a meeting of the Society for Neuroscience in New Orleans. "We've shown that exposure is sufficient to do it in rats, and presumably the same can happen in people," says neurologist Tim Greenamyre, a member of the Emory team.

Parkinson's disease affects one or two adults in every thousand, and the risk increases tenfold beyond the age of 50. Sufferers become clumsy and move stiffly, and their muscles often spasm. These and other symptoms occur because neurons that produce dopamine, a chemical messenger that rouses the body to action, degrade. In addition, fibrous protein deposits called Lewy bodies accumulate in brain cells.

Rotenone is extracted from several plants whose juice has been used by South and Central American people for centuries to catch fish. Unlike synthetic pesticides, it breaks down quickly in the environment, and was thus thought to pose little danger.

To study the physiological effects of rotenone, the pesticide was injected into the bloodstream of laboratory rats. Like many other pesticides, it was known to block the activity of the enzyme needed to provide the dopamine neurons with energy. In the rats, rotenone killed some dopamine neurons and caused deposits resembling Lewybodies.

Benoit Giasson, a Parkinson's disease specialist at the University of Pennsylvania, Philadelphia, points out that the doses given to the rats - and their administration through injection - are very different from the normal human exposure. But he still argues that rotenone should be used with greater caution until more is known about the risks.

Because rats injected with rotenone mirror the symptoms of Parkinson's so closely, the animals will help researchers to study the disease. The work will be published in the December issue of Nature Neuroscience.

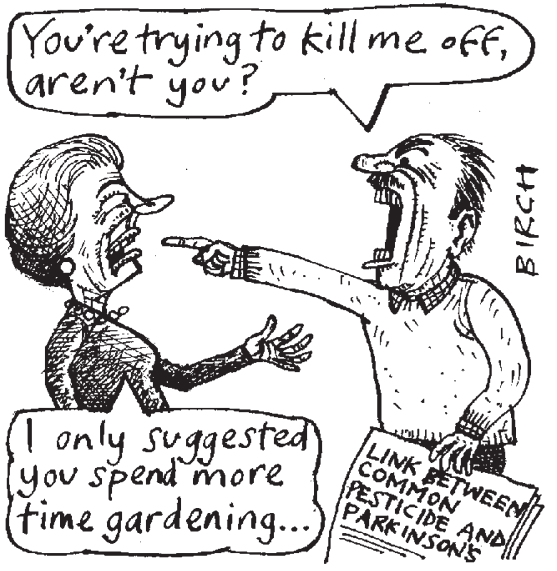

\section{Unprecedented gift boosts basic physics in Canada}

\section{David Spurgeon, Montreal}

An independent institute for research into theoretical physics is being set up in Waterloo, Ontario, thanks to the generosity of a Greek immigrant who made his fortune through creating a high-tech firm that specializes in hand-held electronic communication devices.

The Perimeter Institute for Theoretical Physics is being financed with a donation of Can\$100 million (US\$65 million) from Mike Lazaridis, the 37-year-old founder and joint chief executive officer of Research In Motion.

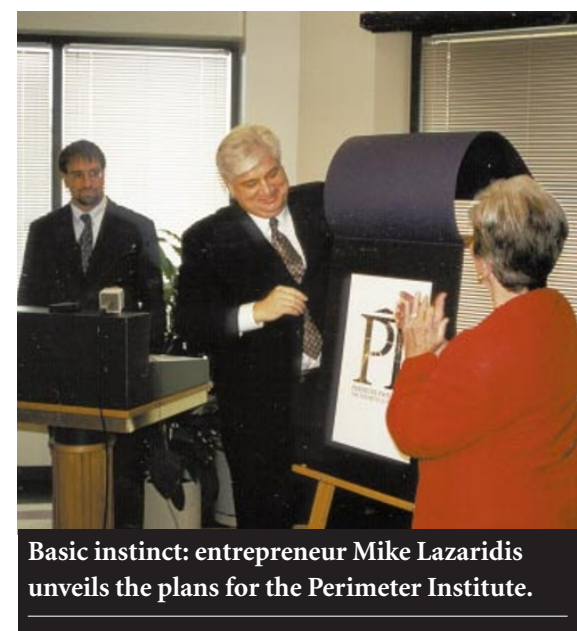

NATURE $\mid$ VOL $408 \mid 9$ NOVEMBER $2000 \mid$ www.nature.com
It is believed to be the largest philanthropic gift in Canadian history and the country's biggest single private contribution in support of basic science.

The institute will be located on a site that will be provided at a nominal rent by the city of Waterloo. The gift from Lazaridis is being supplemented by a further Can\$10 million each from the company's other joint chief executive officer, Jim Balsillie, and its vice-president of operations, Doug Pregin. The initial donations are hoped eventually to become a permanent endowment.

The proposed institute is planned to have links with all of the universities in the region, and will initially operate with a core of between 10 and 15 researchers, who may have joint appointments with other institutions. Areas of research to be covered by the institute include quantum gravity (both string and non-string forms), quantum information theory and quantum computing, elementary particles and fields, and cosmology.

Lazaridis, who arrived in Windsor, Ontario, with his parents in 1967, graduated from the University of Waterloo in electrical engineering and founded Research In Motion in 1984. The company describes itself as "a world leader in the mobile communications market”, and had sales last year of US\$120 million.

Lazaridis says that basic science in Canada is underfunded, and that the gifts will support an area of research that is vital to the technological advances that benefit humankind.

"Just about every major industrial revolution and technical advancement is [rooted] in basic theoretical physics research," he told a press conference announcing the creation of the institute.

He cited research on lasers, wireless technology, computers, semiconductors and superconductors. "It all started with thinkers thinking about problems and laws that are the foundation of our physical world," he said.

The creation of the institute has been described by John Polanyi of the University of Toronto, who won the Nobel prize in chemistry in 1986 for his work on elementary chemical processes, as "a gesture of historic importance for Canadian science". Polanyi described the gift as "entirely out of the mainstream".

Polanyi also called for government to fall into line with its science funding. The federal government of Canada and that of Ontario province are already negotiating with Perimeter officials about their possible involvement, according to its executive director, Howard Burton. 